\begin{tabular}{|c|c|c|c|}
\hline$\underbrace{}_{\text {INESEG }}$ & $\begin{array}{r}\text { International } \\
\text { Res } \\
w w y\end{array}$ & $\begin{array}{l}\text { urnal of Health Services, } \\
\text { rch and Policy } \\
\text { rgipark.org.tr/ijhsrp }\end{array}$ & \\
\hline $\begin{array}{l}\text { ENGINEERING, } \\
\text { SCIENCE AND } \\
\text { EDUCATION GROUP }\end{array}$ & e-ISSN: 2602-3482 & DOI:10.23884/ijhsrp.2019.4.2.03 & IJHSRP \\
\hline
\end{tabular}

Research Article

\title{
THE STUDY OF THE LONG-LIVERS DYNAMICS IN THE POPULATIONS OF ADJARA
} IN 2012-2017

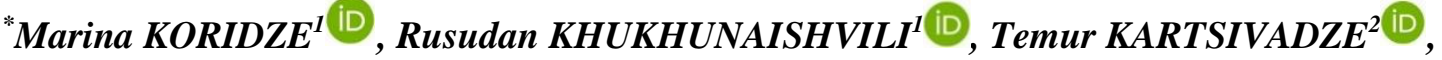 \\ Sophiko TSKVITINIDZE ${ }^{1}$ (D),Irina NAKASHIDZE ${ }^{\text {(i) }}$, Kristine MAKHARADZE ${ }^{1}$ (D) \\ ${ }^{1}$ Batumi Shota Rustaveli State University, Georgia \\ ${ }^{2}$ Socio-medical Socio-medical issues, Georgia \\ Corresponding author: Koridzemarina@gmail.com
}

\begin{abstract}
The life expectancy of human is increasing in almost all over the world, accordingly population aging. Long-liver studies and research about longevity have increased considerably in recent decades and are currently recognized as providing important contributions to the understanding of what can be "successful aging." Population aging is a multidimensional and complex phenomenon and depends as a social, medical as well as genetic factors. The aim of our study was to reveal and statistically process the number of centenarians in the region of Adjara, Georgia since it was known that the mentioned region is famous of long-livers comparing to the other regions of Georgia. At the same time, we were interested in how is the ranging the number of centenarians in 5 years dynamics, in concrete, statistical data of 2012-2017 has been processed. The study has shown that the increase of the long-livers concentration can be observed in all five municipalities of Ajara in the five-years dynamics. Special increase of live longer was observed in Batumi, Khelvachauri and Kobuleti municipalities; The number of centenarians apart from Keda and Shuakhevi municipalities has increased as well. Obtained data have shown that longevity of Ajarian population has been increased and the fact will be useful for further research to identify the main reasons for the multifactorial process of successful aging in Adjara populations.
\end{abstract}

Keywords: longevity, centenarian, long-liver, aging.

Received: May 16, 2019

Accepted: July 3, 2019

\section{Introduction}

In the last decades, it is obvious that the longevity and life expectancy of the human population is increasing in almost all over the world, accordingly it is increasing the median age and population aging. Most of the countries have a rising life expectancy and aging of populations. The aged population is currently at its highest level in human history.[1-2] The United Nations (UN) predicts the rate of population aging in the 21st century will exceed that of the previous century. [2] The number of people aged 60 years and over has tripled since 1950, reaching 600 million in 2000 and surpassing 700 million in 2006. It is projected that the combined senior and geriatric population will reach 2.1 billion by 2050 . [3][4] Countries vary significantly in terms of the degree and pace of aging, and the UN expects populations that began aging later will have less time to adapt to its implications. [2] Globally, considering the total world population, the estimated number of centenarians in 2013 was 441,000; 3.4 million are expected in 2050, and 20.1 million are expected in 2100 [5]. Long-lived studies and research about longevity have increased considerably in recent decades [6] and are currently recognized as 
providing important contributions to the understanding of what can be "successful aging." [7] Human population aging is a multidimensional phenomenon and it differs from aging at the level of individuals. Each additional year individuals are alive, they grow one year older, but defining how populations age is much more complex [1-2]. Through a review of the results of international centenarians' studies, it is possible to determine their main sociodemographic characteristics, health, functionality, and psychosocial features, that can affect or aging. Within the range of various studies, it is possible to be mentioned an extensive number of countries that have already profiled their centenarian population, such as Denmark [ 8], Greece [9], Italy [10], USA [12], Japan [13], Germany [14], Sweden [15], and Australia [16].

The aim of our study at the first stage was to reveal and statistically process the number of centenarians in the region of Adjara, Georgia since it was known that the mentioned region is famous of long-livers comparing to the other region of Georgia. At the same time, we were interested in how is the ranging the number of centenarians in 5 years dynamics, in concrete, the data of 2012-2017 has been processed. Profiling the Adjarian populations in its individuals who have reached 100 years of age is thought to be an important step forward in understanding the longevity process in our country, it would improve the next stages of study connected of long-livers and would challenge the service delivery and various programming for the further considerations.

\section{Material and method}

In order to study the data for long-livers in the Adjara Population and survey the numerical dynamics we have found at social service offices of the Autonomous Republic of Adjara and statistically processed the data of long-livers living in Batumi, Khelvachauri, Kobuleti, Keda, Shuakhevi and Khulo municipalities on the five-year dynamics (2012-2017) including the ones with more than a hundred years of age.

\section{Research outcomes}

\subsection{The Dynamics of the long-livers in Batumi Municipality in 2012-2017}

According to the Adjara Agency of Social Services, the number of people in Batumi municipality is distributed according to the following: 162 people in 2012, 181 - in 2013, 2014-288, 2015-323, 2016-287, and in 2013 - 411. According to the data of the Social Agency of Adjara, the number of centenarians in Batumi municipality according to years is as follows: 2012-2, 2013-3, 20147, 2015-13, 2016-13, 2017-17.

As shown in the Fig.1 in 2012-2017, the concentration of long-livers in Batumi municipality is increasing by the years, the exception is 2016 year. Fig. 2 shows that in the municipalities of Batumi along with the increase in the number of long-livers, the number of centenarians is also increasing.

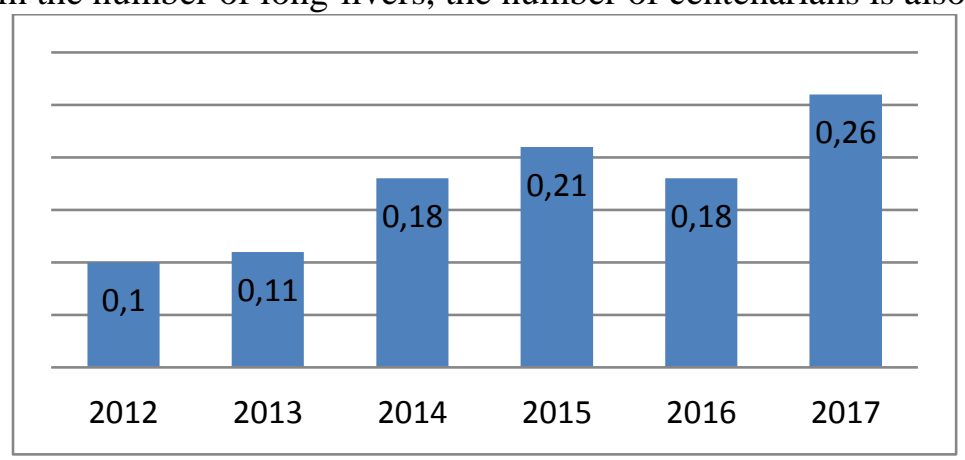

Figure 1. Dynamics (in percentage) of Long-livers in Batumi Municipality in 2012-2017 


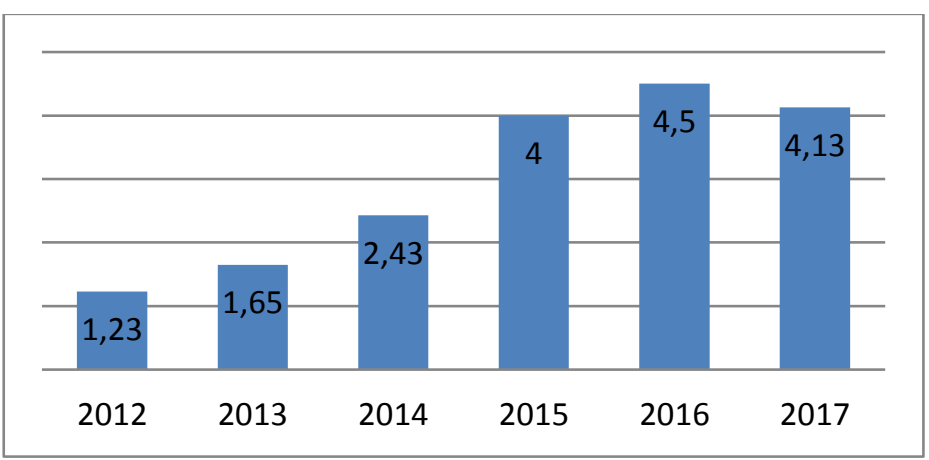

Figure 2. Dynamics (in percentage) of the Centenarians in Batumi municipality in 2012-2017

\subsection{The dynamics of long-livers in Khelvachauri Municipality in $2012-2017$}

According to the data of Adjara Agency of Social Services, the number of long-livers in Khelvachauri municipality is as follows: 136 people in 2012, 145 in 2013, 2014-207, 2015-212, 2016227 and in 2017- 242. According to the data of Adjara Agency of Social Services, the number of centenarians in Khelvachauri municipality is increasing as follows: 2012-5, 2013-6, 2014-8, 2015-10, 2016-11, 2017-12.

In Khelvachauri municipality, in the dynamics of 2012 - 2017 years, the number of the longlivers is moderately growing according to years and the concentration of the centenarians is quite high (Fig.3 and 4)

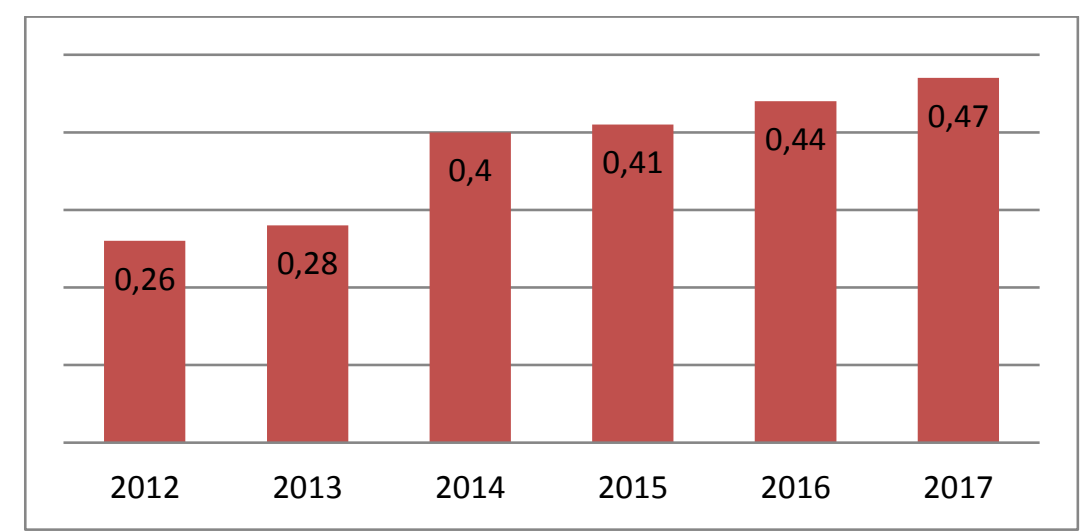

Figure 3. Dynamics (in percentage) of long-livers in Khelvachauri Municipality in 2012-2017

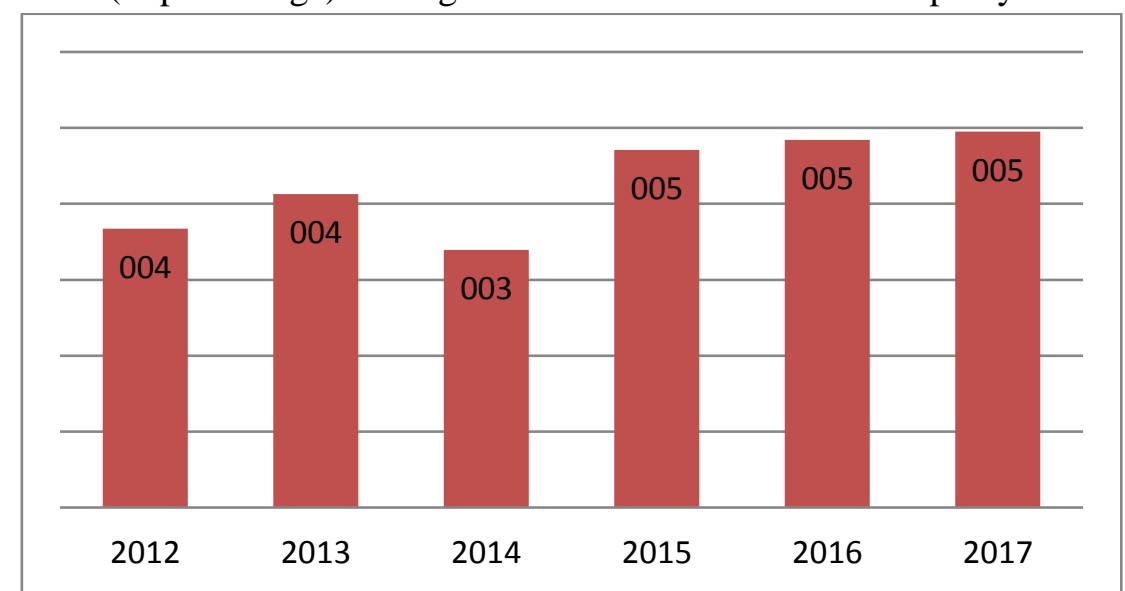

Figure 4. Dynamics (in percentage) of the Centenarians in Khelvachauri Municipality in 2012-2017 


\subsection{The Dynamics of long-livers in Kobuleti Municipality in 2012-2017}

According to the data of Adjara Agency of Social Services, the number of the long-livers in Kobuleti municipality is as follows: 141 people in 2012, in 2013 - 156, 2014-253, 2015-256, 2016-292, and in 2017 - 303.

According to the Ajara Agency of Social Services, the number of centenarians in Kobuleti municipality according to years is as follows: 2012-13, 2013-16, 2014-16, 2015-16, 2016-15, 2017-14.

In Kobuleti Municipality in the dynamics of 2012-2017, despite the increasing number of the long-livers, the number of the centenarians is reduced (Fig.5 and 6).

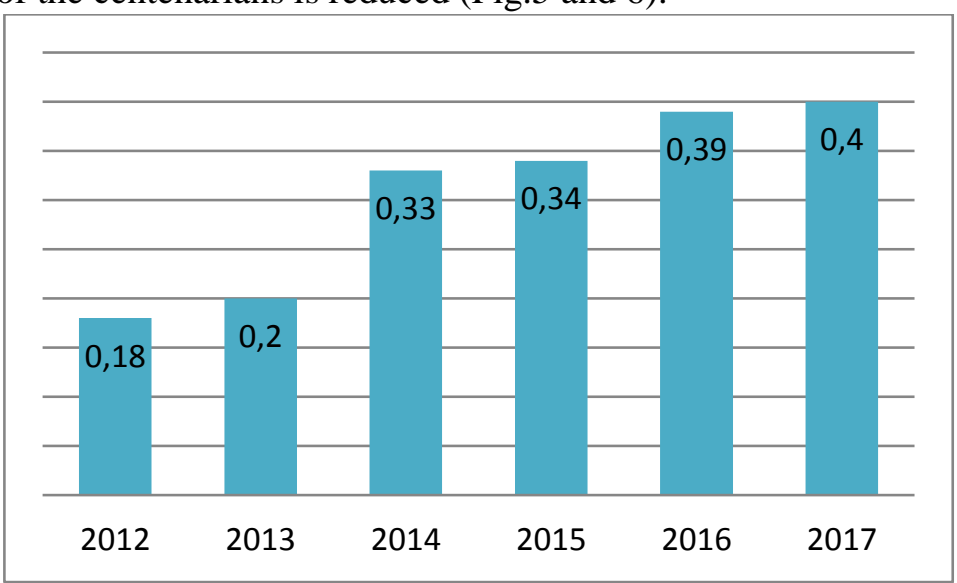

Figure 5. Dynamics (in percentage) of long-livers in Kobuleti Municipality in 2012-2017

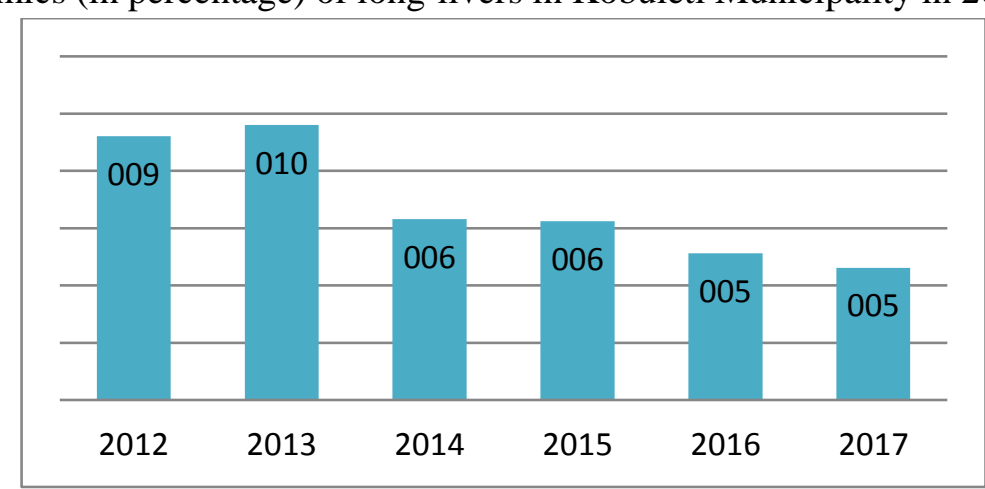

Figure 6. Dynamics (in percentage) of the Centenarians in Kobuleti Municipality in 2012-2017

\subsection{The Dynamics of long-livers in Keda Municipality in 2012-2017}

According to the data of Adjara Agency of Social Services, the number of the long-livers in Keda municipality is as follows: 90 people in 2012, 85 in 2013, 85-585, 2015-93, 2016-91, and in 201797.

According to the Ajara Agency of Social Services, the number of the centenarians in Keda municipality according to years ranges in the following numbers: 2012-8, 2013-8, 2014-7, 2015-7, 2016-5, 2017-3.

The number of long-livers in Keda municipality decreased in 2013 - 2014 years and in recent years the number is increased. The number of centenarians is decreased by the years (Fig.7 and 8). 


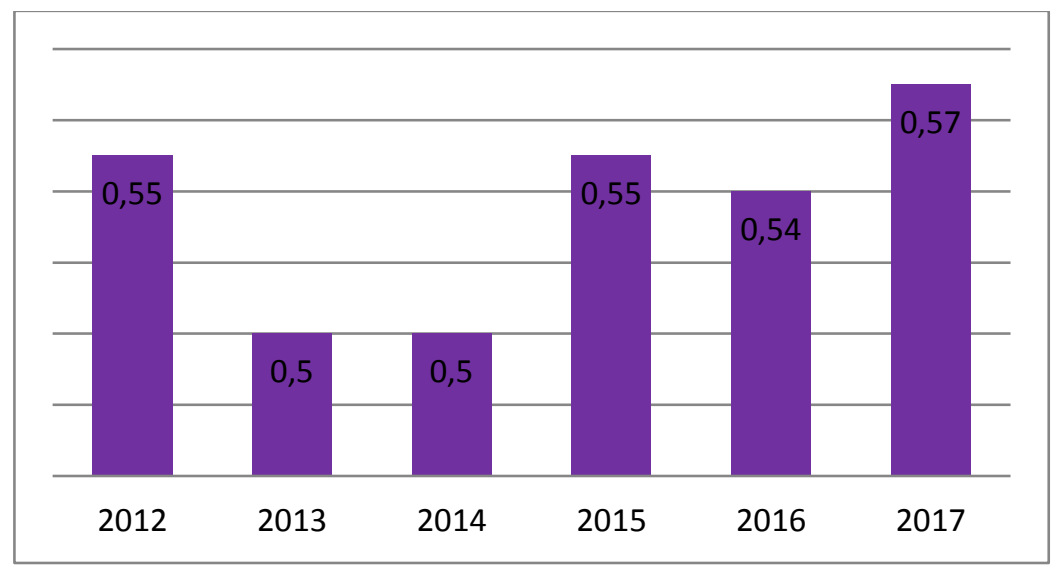

Figure 7. Dynamics (in percentage) of long-livers in Keda Municipality in 2012-2017

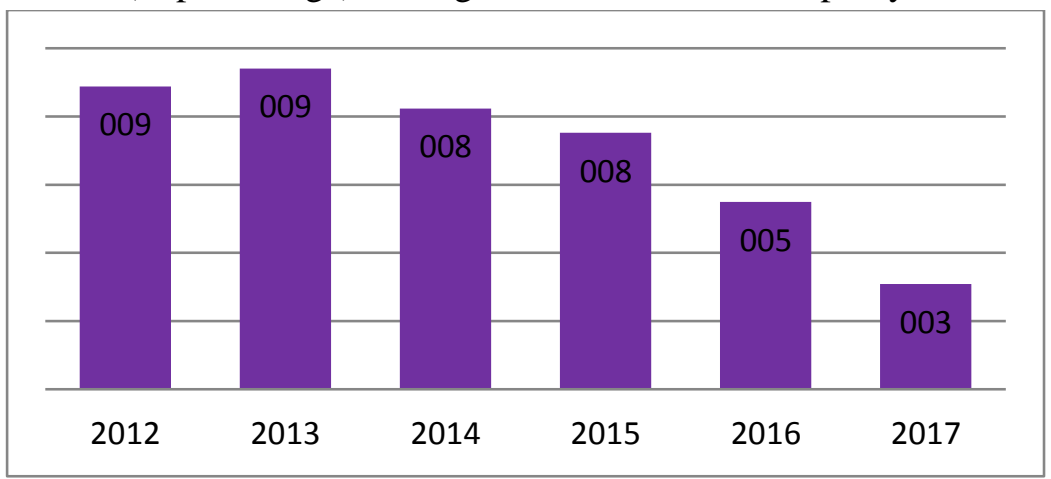

Figure 8. Dynamics (in percentage) of the Centenarians in Keda Municipality in 2012-2017

\subsection{The Dynamics of long-livers in Shuakhevi Municipality in 2012-2017}

According to the data of Adjara Agency of Social Services, the number of the long-livers in Shuakhevi municipality is as follows: 121 people in 2012, in 2013 - 123, 2014-224, 2015-113, 2016123, and in $2017-125$.

According to the data of Adjara Agency of Social Services, the number of centenarians in Shuakhevi municipality is distributed according to years as follows: 2012-12, 2013-11, 2014-10, 20157, 2016-7, 2017-8.

In Shuakhevi municipality there is a slight increase in the concentration of long-livers, the exception is 2015 , as for the centenarians in the abovementioned municipality, their concentration in the five-year dynamics is reduced (Fig 9,10).

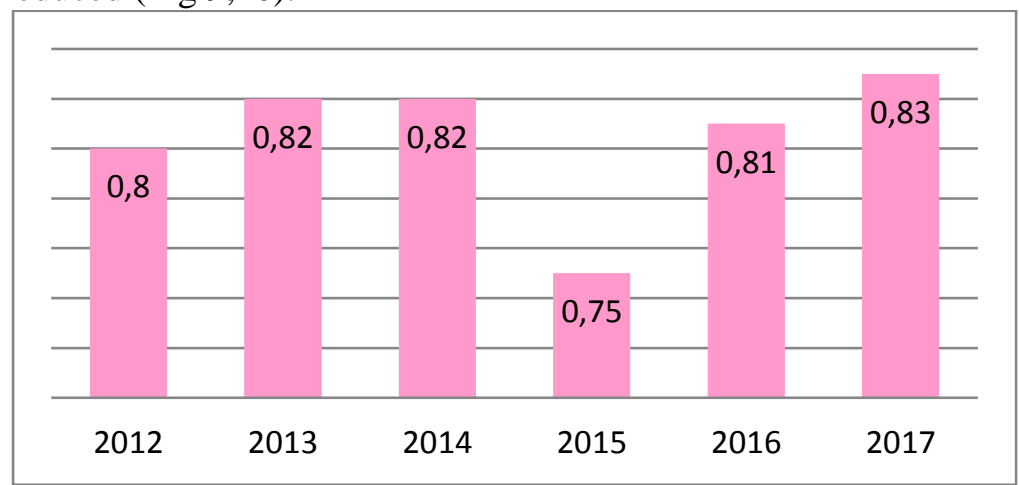

Figure 9. Dynamics (in percentage) of long-livers in Shuakhevi Municipality in 2012-2017 


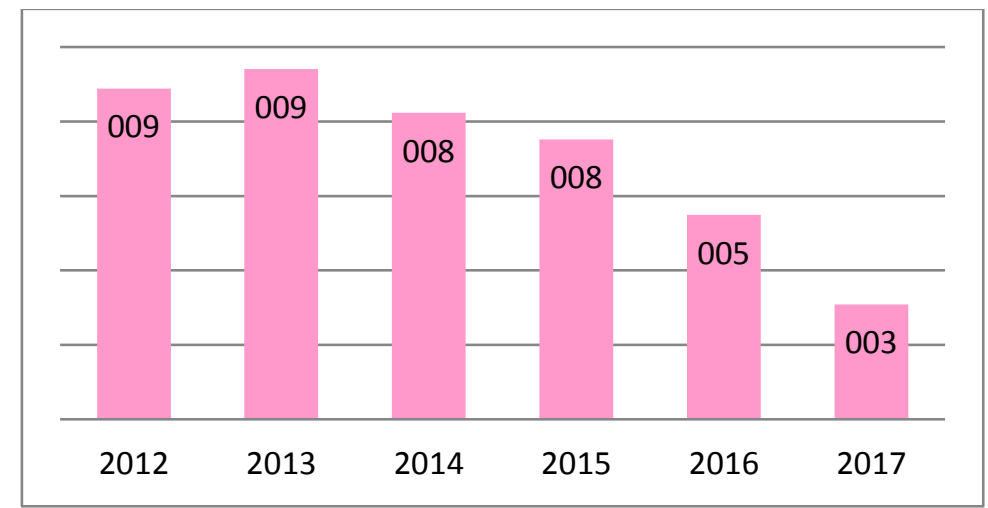

Figure 10. Dynamics (in percentage) of the Centenarians in Shuakhevi Municipality in 2012-2017

\subsection{The Dynamics of long-livers in Khulo Municipality in 2012-2017}

According to the data of Adjara Agency of Social Services, the number of long-livers in Khulo municipality is as following: 173 people in 2012, in 2013 - 166, 2014-163, 2015-168, 2016-181, and in 2017 - 182.

According to the data of the Adjara Agency of Social Services, the number of centenarians according to the years in Khulo municipality is distributed as follows: 2012-11, 2013-13, 2014-12, 201512, 2016-15, 2017-17.

The number of long-livers in the five-year dynamics in Khulo municipality slightly increases, except for the year 2014. In the mentioned municipality the number of centenarians in $2012-2017$ years was increased (Fig.11, 12).

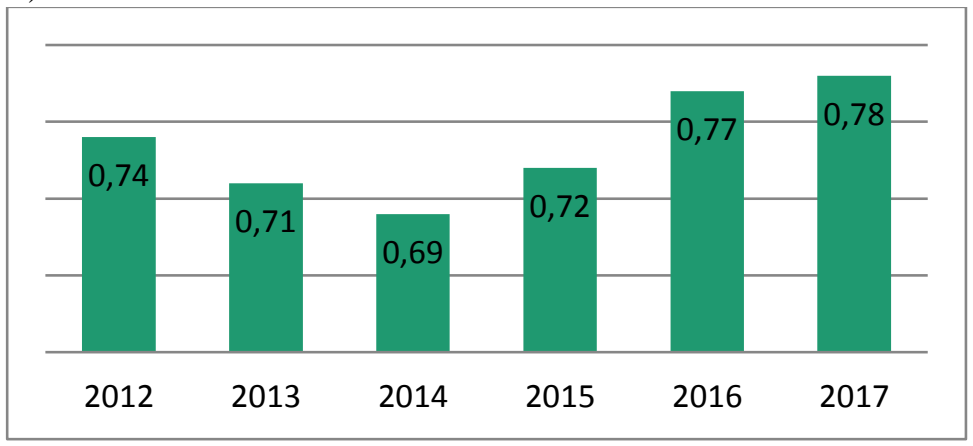

Figure 11. Dynamics (in percentage) of long-livers in Khulo Municipality in 2012-2017

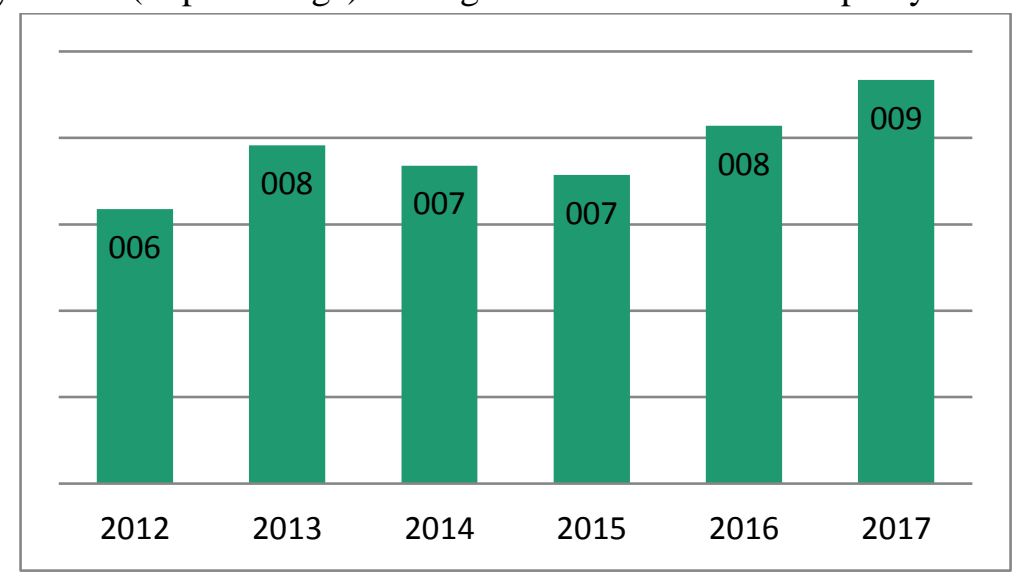

Figure 12. Dynamics (in percentage) of the Centenarians in Khulo Municipality in 2012-2017

\subsection{The Dynamics of long-livers in Adjara Region in 2012-2017}


According to the data of Adjara Agency of Social Services, the number of the long-livers in the Autonomous Republic of Adjara is as follows: 823 people in 2012, 856, 2014-1120, 2015-1165, 20161201 , and in $2013-1360$.

According to the data of the Adjara Agency of Social Services, the number of centenarians in the Municipality of Adjara Autonomous Republic is distributed as follows: 2012-51, 2013-57, 2014-60, 2015-65, 2016-66, 2017-71.

In the five-year dynamics in the Autonomous Republic of Adjara, the quantitative increase of the long-livers was observed, in particular, in 2012 it was $823(0,24 \%)$, and in $2017-1360$ (0.4\%). The number of centenarians has also been increased; in 2012 it was 51 (6.19\%), while in 2017 - $71(5,22 \%)$. The lowest rate is due to the fact that the total number of long-livers is increased.

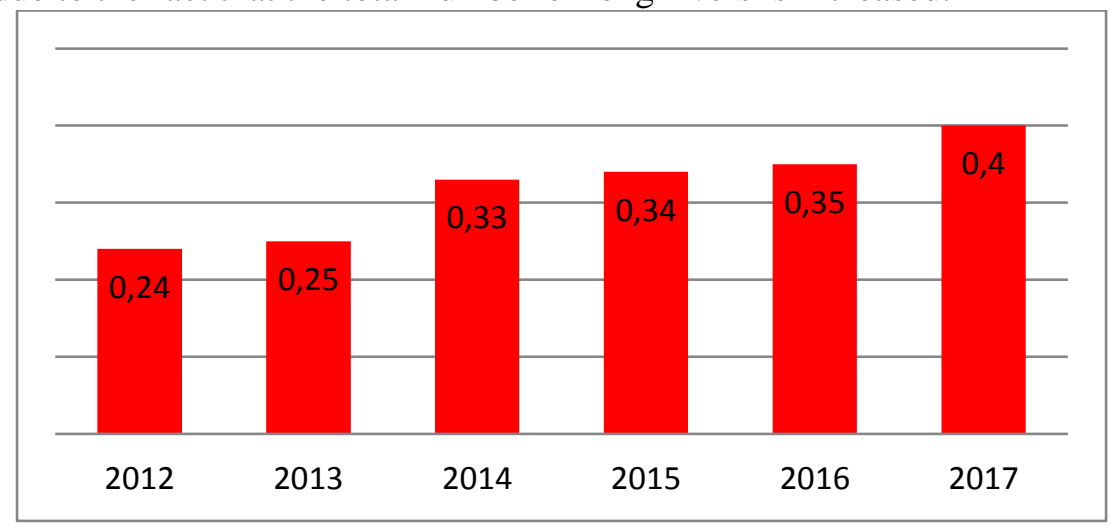

Figure 13. Dynamics (in percentage) of long-livers in Adjara A. R. in 2012-2017

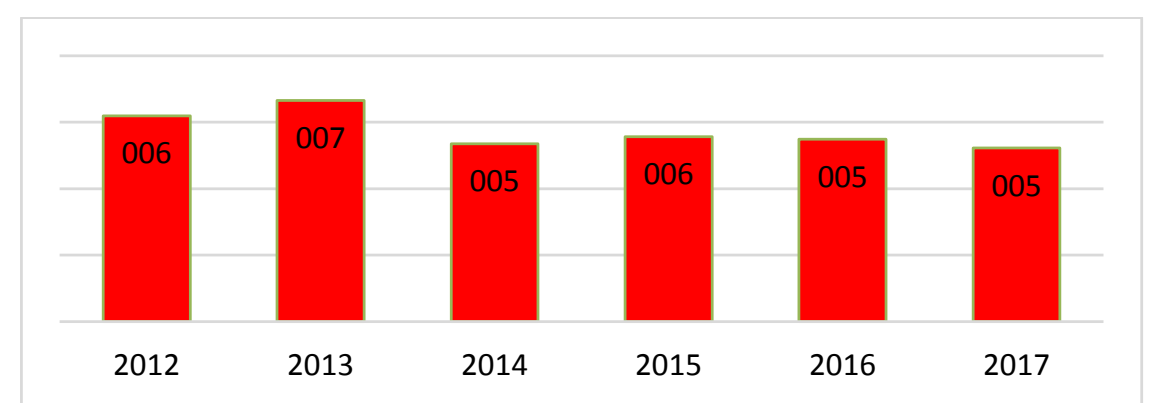

Figure 14. Dynamics (in percentage) of the Centenarians in Adjara A. R. in 2012-2017

Thus, in 2012 -2017, in the five-year dynamics in the Autonomous Republic of Adjara the longlivers concentration was increased; The number of centenarians, apart from Keda and Shuakhevi municipalities is growing according to years; These data coincide with the data taken in different parts of the world, where there is also an increase in the number of long-livers $[7,8,9,10,11,12,13,14,15]$.

\section{Conclusions}

In five years of dynamics (2012-2017) it has been studied the longevity rate in six municipalities of Autonomous Republic of Adjara. With the obtained results we conclude:

* Growth of the long-livers concentration can be observed in five municipalities in the five-year dynamics. The special increase was observed in Batumi, Khelvachauri and Kobuleti municipalities;

* The number of centenarians apart from Keda and Shuakhevi municipalities are growing in 5year duration; 
* The abovementioned data allows the implementation of the next steps of the research, where it will be possible to search and identify the main causes of the multifactorial process of aging which led to the increase the lifespan and the longevity 5 years duration in the Adjara populations.

\section{References}

[1]. Sanderson WC, Scherbov S. "Average remaining lifetimes can increase as human populations age”, Nature, 435, 811-813, 2005. doi: 10.1038/nature03593 [PubMed]

[2]. Sanderson WC, Scherbov S. "The characteristics approach to the measurement of population aging" Popul Dev Rev., 39, 673-685, 2013. doi: 10.1111/j.1728-4457.2013.00633.x

[3]. Chucks, J (July 2010). "Population Ageing in Ghana: Research Gaps and the Way Forward". Journal of Aging Research, 1,8-17, ,2010. doi:10.4061/2010/672157.

[4]. World Population Ageing: 1950-2050, United Nations Population Division.

[5]. Instituto Nacional de Estat'istica, "Populac, ao residente por Local de resid`encia, Sexo e Grupo et'ario (Decenal)," http:// www.ine.pt/xportal/xmain?xpid=INE\&amp;xpgid=ine indicadores \& amp; indOcorrCod $=0006368 \&$ amp; contexto=bd\&amp; selTab=tab2.

[6]. L. Poon and S. Cheung, "Centenarian research in the past two Decades," Asian Journal of Gerontology \&Geriatrics, 7, 13-18, 2012.

[7]. R. M. Afonso, O. Ribeiro, M. V. Patto, M. Loureiro, M. J. Loureiro, M. Castelo-Branco, S. Patrício, S. Alvarinhas, T. Tomáz, C. Rocha, A. M. Jerónimo, F. Gouveia, A. P. Amaral, "Reaching 100 in the Countryside: Health Profile and Living Circumstances of Portuguese Centenarians from the Beira Interior Region Hindawi”, Current Gerontology and Geriatrics Research, Vol. 2018, Article ID 8450468, 11 pages, 2018, https://doi.org/10.1155/2018/8450468

[8]. H. Engberg, A. Oksuzyan, B. Jeune, J. W. Vaupel, and K. Christensen, "Centenarians - A useful model for healthy aging? A 29-year follow-up of hospitalizations among 40000 Danes born in 1905," Aging Cell, 8(3), 270-276, 2009.

[9]. C. Darviri, P. Demakakos, F. Charizani et al., "Assessment of the health status of Greek centenarians," Archives of Gerontology and Geriatrics, 46(1), 67-78, 2008.

[10]. M. Motta, L. Ferlito, S. U. Magnolfi, et al., "Cognitive and functional status in the extreme longevity," Archives of Gerontology and Geriatrics, 46(2), 245-252, 2008.

[11]. T. T. Perls, K. Bochen, M. Freeman, L. Alpert, and M. H. Silver, "Validity of reported age and centenarian prevalence in New England," Age and Ageing, 28(2),193-197, 1999.

[12]. B. J. Willcox, D. C. Willcox, and L. Ferrucci, "Secrets of healthy aging and longevity from exceptional survivors around the globe: Lessons from octogenarians to supercentenarians," The Journals of Gerontology. Series A, Biological Sciences andMedical Sciences, 63(11), 1181-1185, 2008.

[13]. D. Jopp and C. Rott, "Adaptation in very old age: Exploring the role of resources, beliefs, and attitudes for centenarians' happiness," Psychology and Aging, 21(2), 266-280, 2006.

[14]. S. M. Samuelsson, B. Bauer Alfredson, B. Hagberg, et al., "The Swedish Centenarian Study: A multidisciplinary study of five consecutive cohorts at the age of 100," International Journal of Aging and Human Development, 45(3), 223-253, 1997.

[15]. T. Koch, R. Turner, P. Smith, and N.Hutnik, "Storytelling reveals the active, positive lives of centenarians," Nursing Older People, 22(8), 31-36, 2010. 